needed to be more risk based and that risk management decision making should be more open and transparent, with clearer and wider communication of the surveillance data. The Department for Environment, Food, and Rural Affairs (Defra) launched its new Veterinary Surveillance Strategy in 2003, putting at its core the protection of public health in relation to food and animal diseases transmissible to people.

Thirdly, the integration of human and animal health is vital for the analysis of data on human and animal infections and the sharing of this information with all those who have a role in managing risks and threats to public health. This is reflected in the existence of various joint expert advisory committees, official working groups, stakeholder groups, and international partnerships, which often consider specific issues contemporaneously (see bmj.com for detailed examples).

There is a risk, of course, that this large number of partnerships could, if not working cooperatively, hinder rather than help the implementation of an effective response to a new zoonotic infection. It is essential, therefore, that when a new, potentially zoonotic, and acute risk emerges these links can be "fast tracked," and mechanisms are in place that allow rapid assessment of the risks by using agreed methods for consistency, particularly when the risks to health are unclear.

A recent example of how the various groups work together is the development of health protection measures after the emergence of avian influenza. Independent advice was sought from the expert Joint Committee on Vaccination and Immunisation on the use of seasonal flu vaccine for poultry workers and others at risk groups and from the Advisory Committee on
Dangerous Pathogens on the wider risks associated with exposure of the public or workers to $\mathrm{H} 5 \mathrm{~N} 1$ and other influenza viruses. In this context, staff embraced all sectors from agriculture to the NHS. The advice received has been made public and has been used to produce specific guidance for affected industry groups.

Examples of other collaborative working on zoonotic diseases, coordinated through the UK Zoonoses Group, are the development of common standard operating procedures by the veterinary and public health Laboratory Test Group for the isolation, identification, and typing of bacterial, viral, and parasitic organisms and for antibiotic sensitivity testing, and the development of shared databases incorporating phenotypic and molecular information from human and animal sources. Other projects integrating human and animal health, such as the harmonisation of procedures for the surveillance of animal and human infectious disease and the cross training of veterinary and public health staff in new techniques for handling new or unusual zoonotic pathogens, increase our ability to scale up laboratory diagnostics should the need arise.

These diverse and cooperative ways of working across the animal and human health spectrum allow us to identify, and develop measures to better manage, animal or human disease threats that may arise either within the UK or globally.

Debby Reynolds chief veterinary officer

Department for Environment, Food, and Rural Affairs, Nobel House, London SW1P 3JR (cvo-uk@defra.gsi.gov.uk)

Liam Donaldson chief medical officer

Department of Health, Richmond House, London SW1A 2NL

Competing interests: None declared.

\title{
Foodborne zoonoses
}

\section{Food poisoning can be serious, and doctors and vets have key roles in tackling it}

$\mathrm{F}$ oodborne disease (food poisoning) tends to be regarded as a comedy illness-not pleasant to have, or talk about, but little more than an inconvenience. Yet trivialising foodborne disease ignores the size of the illness burden: estimates vary from 76 million cases of foodborne disease annually in the United States ${ }^{1}$ to 5.4 million in Australia ${ }^{2}$ and 1.3 million in England and Wales. ${ }^{3}$ Three of the major pathogens-Campylobacter spp, Salmonella spp, and Shiga toxin producing Escherichia coli O157 (STEC O157)-are zoonoses (that is, transmitted from vertebrate animals to humans). As well as causing acute symptoms including diarrhoea and vomiting, infection can have long term implications.

Campylobacter is the principal bacterial cause of gastroenteritis in the developed world. The World Health Organization estimates that about $1 \%$ of the population of Europe will be infected with Campylobacter spp each year. In England and Wales about 45000 acute cases are diagnosed annually. Infection is associated with development of Guillain-Barré syn- in polio-free regions in the world. ${ }^{4}$ The risk of developing it after campylobacter infection is about 1 in 1000 (the risk rising to around 1 in 160 for infections with certain serotypes). ${ }^{5}$ Both campylobacter and salmonella infections can result in reactive arthritis, although the precise mechanisms are still unclear, and infection with STEC O157 is a leading cause of haemolytic uraemic syndrome, the most common preventable trigger for acute renal failure in children. ${ }^{6}$

Clinical management of patients with acute symptoms of foodborne disease in primary care is generally the same regardless of aetiology (rest and rehydration), and treatment with antimicrobials is rarely indicated for uncomplicated diarrhoea. For example, there is no evidence that antibiotic treatment of uncomplicated salmonella diarrhoea in otherwise healthy children and adults is beneficial, and it may even prolong salmonella carriage. ${ }^{7}$ Antimicrobial treatment in cases of STEC O157 infection might do positive harm, potentially precipitating the onset of haemolytic uraemic syndrome. ${ }^{8}$ Limiting inappropriate 


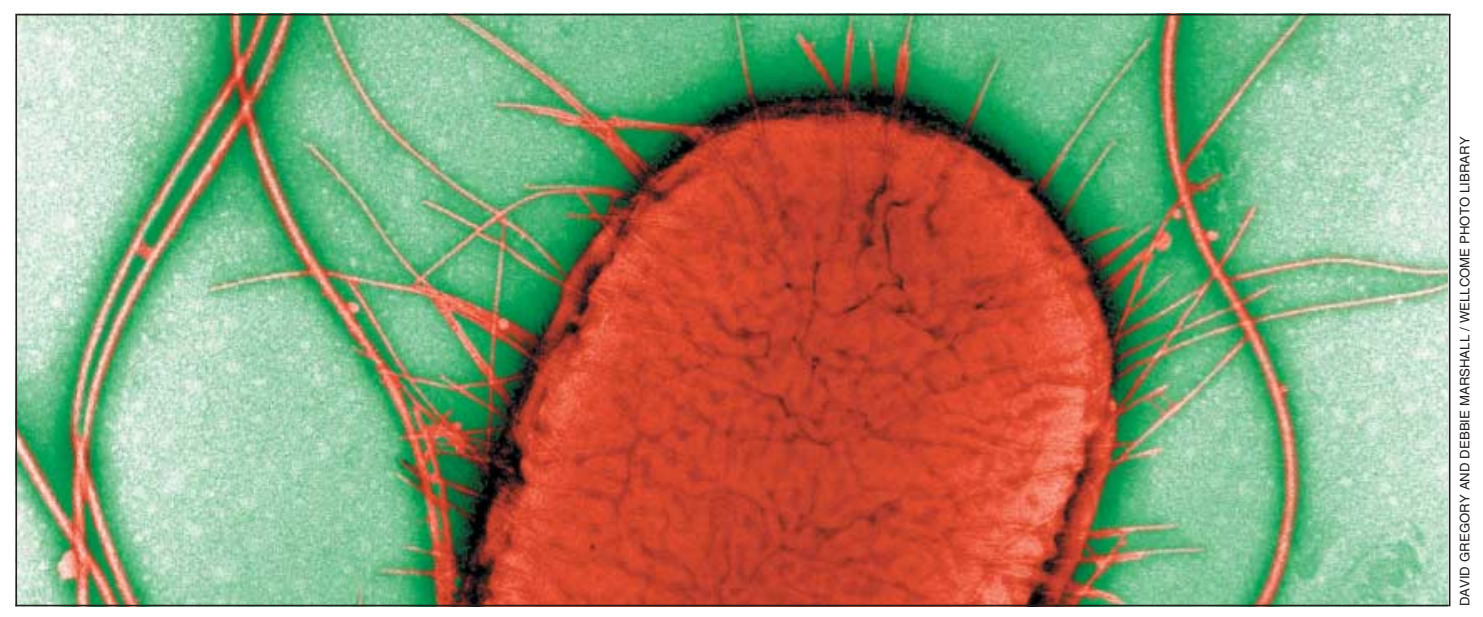

False colour scanning electron micrograph of $E$ coli, showing pili

antimicrobial use also has broader public health benefits.

Although knowing the causative organism might not affect clinical management, it is vital for public health protection, and primary care is in the front line as regards outbreak detection. Differentiating infection with foodborne zoonoses from other causes of acute diarrhoea is not always easy, but clinical acumen, appropriate laboratory tests, and prompt alerts to local health protection teams allow public health professionals to assess whether an apparently sporadic case is simply that or whether it is necessary to initiate the detailed detective work required to track an outbreak to its source. Clinical, epidemiological, microbiological, and environmental studies require the combined effort of doctors and vets, alongside laboratory and environmental health colleagues.

Epidemiological studies of sporadic infection also yield important clues about transmission paths and potential sources. The now familiar association between Salmonella enteritidis phage type 4 infection in humans and consumption of poultry eggs ${ }^{9}$ was revealed through such endeavour. More than a decade after those observations were published in the $B M J$, the epidemic of infection in humans is seemingly coming under control. However, a continued public health challenge is to ensure that good work undertaken by UK industry is not jeopardised by buying contaminated products from overseas. ${ }^{10}$

Primary prevention of foodborne zoonoses is mainly a veterinary responsibility. However, organisms causing human illness do not necessarily have animal health implications-campylobacter and STEC O157 are cases in point. Surveillance data amassed from clinical investigations can help policy makers target resources. For example, the Food Standards Agency's campaign "Cleaner farms, better flocks" reflects the fact that reducing the impact of UK foodborne disease chiefly depends on controlling campylobacter contamination of chickens. ${ }^{11}$ Safeguarding the flow of surveillance data remains a priority in the wake of developments in data protection, and in changes to the delivery of primary care, including the introduction of telephone triage systems.

Like all communicable diseases, foodborne zoonoses do not respect administrative or professional boundaries. Acknowledging the importance of an integrated approach to investigation and control of zoonoses, including foodborne zoonoses, several European countries have formed unified administrative structures. Although this has not formally happened in the UK, a combined approach at government level has led to several initiatives, including the production of UK zoonoses reports (available at www.defra.gov.uk/animalh/diseases/ zoonoses/reports.htm).

It is, perhaps, worth reflecting that vets and doctors form either end of a chain (from primary prevention at one end to dealing with its failures at the other) and that decisions made by many others along the food chain, including in the food industry (primary production, retail, and catering) affect our exposure to foodborne pathogens. The recent outbreak of STEC $\mathrm{O} 157$ in Wales ${ }^{12}$ serves as a timely reminder of the importance of foodborne zoonoses and of the collaborative efforts needed to control them.

Sarah J O'Brien professor of health sciences and epidemiology

Division of Medicine and Neurosciences, University of Manchester

School of Medicine, Hope Hospital, Salford M6 8HD

(sarah.o'brien@manchester.ac.uk)

Competing interests: SJO'B is a member of the Advisory Committee on the Microbiological Safety of Food.

1 Mead PS, Slutsker L, Dietz V, McCaig LF, Bresee JS, Shapiro C, et al. Food-related illness and death in the United States. Emerg Infect Dis 1999;5:607-25.

2 Hall G, Kirk MD, Becker N, Gregory JE, Unicomb L, Millard G, et al. Estimating foodborne gastroenteritis, Australia. Emerg Infect Dis 2005;11: 1257-64

3 Adak GK, Long SM, O'Brien SJ. Trends in indigenous foodborne disease and deaths, England and Wales: 1992 to 2000. Gut 2002;51:832-41.

4 Nachamkin I. Chronic effects of Campylobacter infection. Microbes Infect 2002;4:399-403.

5 Allos BM. Association between Campylobacter infection and GuillainBarré syndrome. J Infect Dis 1997;176(suppl 2): S125-8.

6 Elliott EJ, Robins-Browne RM. Hemolytic uremic syndrome. Curr Probl Pediatr Adolesc Health Care 2005;35:310-30.

7 Pediatr Adotesc Health Care 2005;35:310-30. Sirinavin S, Garner P. Antibiotics for treating
Cochrane Database Syst Rev 2000;2:CD001167.

8 Tarr PI, Gordon CA, Chandler WL. Shiga-toxin-producing Escherichia coli Tarr PI, Gordon CA, Chandler WL. Shiga-toxin-producing Escher
and haemolytic uraemic syndrome. Lancet 2005;365:1073-86.

9 Cowden JM, Lynch D, Joseph CA, O'Mahony M, Mawer SL, Rowe B, et al. Case-control study of infections with Salmonella enteritidis phage type 4 in England. BMJ 1989;299:771-3.

10 Health Protection Agency. Salmonella enteritidis non-phage type 4 infections in England and Wales: 2000 to 2004-report from a multi-agency national outbreak control team. CDR Weekly [serial online] 2004;14(42). www.hpa.org.uk/cdr/PDFfiles/2004/cdr4204.pdf (accessed 14 Nov 2005).

11 Adak GK, Meakins SM, Yip H, Lopman BA, O'Brien SJ. Disease risks from foods, England and Wales, 1996-2000. Emerg Infect Dis 2005;11: 365-72.

12 E coli breaks out in Wales. BMJ 2005;331:714. 